\title{
Factors Associated with Mortality in Critically III Patients Diagnosed with Hospital Acquired Infections
}

This article was published in the following Dove Press journal:

Infection and Drug Resistance

\section{Matheus L Otero,' Rodrigo C Menezes, ${ }^{2}$ Isabella B B Ferreira, ${ }^{3}{ }^{3}$ Francine L Issa, ${ }^{4}$ Gabriel Agareno,' Thomas Azevedo Carmo, (D) ' María B Arriaga, ${ }^{4-6}$ Kiyoshi F Fukutani, ${ }^{5,6}$ Licurgo Pamplona Neto, ${ }^{7}$ Sydney Agareno, ${ }^{7}$ Nivaldo $M$ Filgueiras Filho, ${ }^{1,3,7}$ * Kevan M} Akrami, ${ }^{8} *$ Bruno B Andrade iD ${ }^{1,4-6,9, *}$

'Curso de Medicina, Universidade Salvador (UNIFACS), Laureate Universities, Salvador, Bahia, Brazil;

${ }^{2}$ Curso de Medicina, União Metropolitana Para o Desenvolvimento da Educação e Cultura (UNIME), Salvador, Bahia, Brazil; ${ }^{3}$ Universidade Do Estado Da Bahia (UNEB), Salvador, Bahia, Brazil; ${ }^{4}$ Curso de Medicina, Universidade do Estado da Bahia, Salvador, Bahia, Brazil; ${ }^{5}$ Laboratório de Inflamação e Biomarcadores, Instituto Gonçalo Moniz, Fundação Oswaldo Cruz,

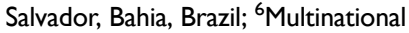
Organization Network Sponsoring Translational and Epidemiological Research (MONSTER) Initiative, Salvador, Bahia, Brazil; ${ }^{7}$ Hospital Da Cidade, Intensive Care Unit, Salvador, Bahia, Brazil; ${ }^{8}$ Division of Infectious Diseases and Pulmonary Critical Care and Sleep Medicine, Department of Medicine, University of California, San Diego, California, USA; ${ }^{9}$ Escola Bahiana De Medicina e Saúde Pública (EBMSP),

Salvador, Bahia, Brazil

*These authors contributed equally to this work

Correspondence: Bruno B Andrade Laboratório De Inflamação e Biomarcadores, Instituto Gonçalo Moniz, Fundação Oswaldo Cruz, Rua Waldemar Falcão No. I2I, Candeal, Salvador, Bahia 40269-7I0, Brazil Email bruno.andrade@fiocruz.br
Objective: Evaluate host and pathogen factors associated with mortality in those with hospital acquired infections (HAI) in a tertiary intensive care unit in Brazil.

Methods: Observational and analytical cohort single center study in a general intensive care unit (ICU) in Northeastern Brazil between January 2016 and August 2018, including those over 18 years of age admitted to the ICU found to have a HAI.

Results: A total of 165 patients were included, with a mean age of 72 years and male predominance $(53.3 \%)$ and observed mortality of $46 \%$. Mortality in those with HAI was significantly associated with older age, increased ICU length of stay and readmission to the ICU in univariate analysis. Multivariate analysis revealed that development of septic shock and obtundation during ICU admission was significantly associated with an increased risk of death (OR: 6.94, 95\% CI 1.23-39.27, OR: 2.48, 95\% CI 1.17-5.29, respectively). A trend towards mortality risk was noted in those with increased age and prior cardiovascular disease. Surprisingly, mortality risk was independent of site of infection, type of pathogen and antibiotic resistance. Furthermore, having more than one HAI over the course of the ICU admission did not impact mortality.

Conclusion: Risk of death in those with HAI is associated with obtundation and septic shock, in addition to vasopressor use. Host factors, rather than pathogen-specific characteristics or infecting site, impact risk of death related to HAI in the ICU.

Keywords: hospital acquired infection, ICU, mortality, critical illness, septic shock, intensive care

\section{Introduction}

A critical challenge has emerged in intensive care units (ICU) worldwide to prevent infections after admission or related to diagnostic and/or therapeutic procedures. Numerous bundles have been developed to address this issue with variable success (eg head of bed elevation, chlorhexidine oral care). ${ }^{1}$ Despite these efforts, hospital acquired infections (HAI) in the ICU continue to occur at a relatively high rate. These infections are associated with significant in-hospital mortality and morbidity that lead to prolonged hospital stay and increased healthcare costs. Critically ill patient co-morbidities and types of infecting pathogens have been shown to impact complications related to HAIs, often leading to more severe and life-threatening outcomes. ${ }^{2}$ Long-term treatment with antibiotics and subsequent infection with multi-drug resistant bacteria has been implicated in increased ICU mortality in those with HAIs. ${ }^{3}$ Compounded with increasing HAI incidence, a multi-national European study identified the emergence of multi-drug resistance, particularly among Gram negative bacteria. ${ }^{4}$ Furthermore, prior work noted the critical role of 
HAIs in the development of in-hospital septic shock and death if not rapidly recognized and appropriately treated, particularly in critically ill patients. ${ }^{5}$

While much work has been done to elucidate complications related to HAIs, few studies to date have evaluated factors associated with ICU mortality in those with HAIs in Brazil. $^{6-8}$ ANVISA, the Health Regulatory National Agency, publishes the Patient Safety and Quality in Health Services bulletin on the incidence of central line associated bloodstream infections (CLABSI), catheter associated urinary tract infections (UTI), ventilator associated pneumonia (VAP) and surgical site infection (SSI). A Brazilian study in 2015 noted a mortality rate of $38.4 \%$ in those with HAI, while HAI was considered a contributing factor in $87.1 \%$ of those who died. Moreover, mortality in those with HAI was associated with comorbidities, invasive procedures, pneumonia, endocarditis and infection with resistant microorganisms. ${ }^{6}$ The current study seeks to determine factors associated with ICU mortality in a critically ill population with HAIs.

\section{Methods}

This was a retrospective cohort study in a tertiary ICU in Salvador, Brazil conducted from January 2016 to August 2018. All patients over 18 years of age with a confirmed HAI during ICU admission were included. Patients with missing data were excluded. Clinical data was prospectively collected at time of admission through an electronic medical record for all admitted ICU patients. Microbiological data and determination of hospital acquired infection was provided by the infection control department in accordance with national guidelines (ANVISA). HAIs were defined as infections not present at admission that developed on or after the 3rd calendar day of ICU admission. In patients admitted to the ICU more than once during their hospitalization, data was analyzed only for the first ICU admission.

The following data was collected at admission: age, gender, body mass index (BMI), total length of ICU and hospital stay, admission classification (clinical or surgical), main ICU diagnosis, co-morbidities, severity score calculation (SAPS 3), major location of infection (central line associated bloodstream infection, urinary tract infection, respiratory infection and skin), microorganisms isolated in cultures (Gram positive bacteria, Gram negative bacteria, Candida or none), and presence of resistance to antimicrobials. The vital status at the end of the stay in the unit was considered the main result.

Additional clinical data collected: vital signs and laboratory data from the first 6 hours of admission, including mean arterial pressure (MAP), heart rate, respiratory rate, temperature, Glasgow coma score, BRADEN, FOUR, RASS sodium, potassium, ionized calcium, hematocrit, white blood cell (WBC) count with differential, platelet count, C-reactive protein (admission and highest during the ICU stay), creatinine, blood urea nitrogen (BUN), direct bilirubin, $\mathrm{pH}, \mathrm{PaO} 2, \mathrm{PaCO} 2, \mathrm{FiO} 2$, $\mathrm{PaO} 2 / \mathrm{FiO} 2$ and lactate. Supportive ICU therapy and interventions including use of inotropes or vasopressors, mechanical ventilation and dialysis were noted.

Categorical variables are presented as frequencies and percentages, while continuous variables are presented as group-specific mean and standard deviations for normally distributed variables, and median and interquartile range for non-normally distributed variables.

Median and interquartile ranges (IQR) were used as measures of central tendency. Frequencies were compared using the Pearson's chi-squared test. Continuous variables were compared using the Mann-Whitney U-test (between two groups) or the Kruskal-Wallis test with Dunn's multiple comparisons (between $>2$ groups). Correlations were tested using the Spearman's rank correlation test.

All variables with $p<0.20$ by univariate logistic regression were evaluated in a multivariable logistic regression model and sequentially removed using backward selection until all remaining variables had $p<0.10$ to assess for confounding factors. Odds ratios with $95 \%$ confidence intervals were used as force measurements for the correlations.

To assess for direct and indirect relationships amongst all variables and mortality outcomes, Bayesian network learning was used to describe and visualize conditional dependencies between the multiple clinical and laboratorial variables. $P$-values were adjusted for multiple comparisons using the Holm-Bonferroni method. ${ }^{9}$ All analyses were prespecified. Two-sided $p$-value $<0.05$ after adjustment for multiple comparisons were considered statistically significant. Continuous variables were discretized by Hartemink's algorithm accessed by "bnlearn" package in R 3.1.057. ${ }^{10}$ The learning algorithm used to establish the network structure was based on the heuristic hill climbing method. ${ }^{11}$ The dependencies represented qualitatively by a directed acyclic graph where each node corresponds to a variable and a direct arc between nodes represents a direct influence. Robustness of the arcs was scored by a nonparametric bootstrap test $(100 \times$ replicates $){ }^{12}$ Arcs with more than $20 \%$ support were depicted. The strongest associations were considered those remaining statistically significant in 
$\geq 20 \%$ bootstraps. Statistical analyses were performed using SPSS 25.0 (IBM Corporation, Waltham, MA, USA), GraphPad Prism 6.0 (GraphPad Software Inc., La Jolla, CA, USA) and JMP 12.0 (SAS Institute Inc., Cary, $\mathrm{NC}$, USA).

\section{Results}

Of the 1671 patients admitted to the ICU during the study period, 227 had confirmed HAI and 62 individuals without complete admission data were excluded, yielding a final cohort of 165 patients. Mean age was $70 \pm 17$ years old, $53.3 \%$ were men, and most patients were admitted from the emergency room $84(50.9 \%)$ with a cardiovascular 29 $(17.6 \%)$ or infectious $58(35.2 \%)$ diagnosis. ICU mortality rate differed significantly based on HAI status, a median mortality of 14\% (12.05-35.59) was predicted by SAPS 3 whereas $76(46 \%)$ patients died in the HAI cohort compared to $322(14 \%)$ in the overall ICU population. A considerable proportion of our cohort required mechanical ventilation, 59 (35.8\%). Additional characteristics are highlighted in Table 1.

Statistically significant differences in mortality were observed in those with older age, longer ICU length of stay and readmission to the ICU within $48 \mathrm{~h}$ after discharge. Clinical parameters that were significantly more associated with deaths during the ICU admission included lower mean arterial pressure, lower Glasgow coma scale (GCS), lower platelet count and higher C-reactive protein. (Table 1)

Site of infection, pathogen, antimicrobial resistance and multiple HAIs were not statistically significant. Central line associated bloodstream infections (CLABSI) were the most frequent type of HAI noted in 59 (35.8\%) patients, followed by respiratory tract infections in 48 (29.1\%), urinary tract infections (UTI) in 46 (27.9\%) and skin infections in three $(1.8 \%)$. Twenty-eight patients (17\%) had more than one infection, $25(15.2 \%)$ with two infections, and three $(1.8 \%)$ with three infections or more during the same ICU admission. The most common bacteria isolated were gram negatives in 74 (44.8\%) patients followed by gram positives in $39(23,6 \%)$ and Candida in six $(3.6 \%)$, while $46(27.9 \%)$ patients did not have a pathogen isolated. A total of $46(27.9 \%)$ of the isolated pathogens were noted to have resistance to at least one class of antibiotics.

Significant factors identified in univariate analysis were analyzed in a multivariate regression model to assess for possible confounders (Figure 1). According to our model, the following factors were significantly associated with mortality in our HAI cohort at time of ICU admission: obtundation (OR 2.48, 95\%CI: 1.17-5.29, $p=0.018$ ) and septic shock (OR: 6.94, 95\%CI: 1.23-39.27, $p=0.028$ ). Bayesian network analysis recapitulated the regression findings that infection with resistant organisms does not have a direct or indirect association with ICU mortality. Multiple HAIs, while directly associated with ICU length of stay, did not robustly associate with ICU mortality. Bayesian network analysis revealed that septic shock, in contrast to our regression analysis, did not robustly associate with ICU mortality. Interestingly, acute kidney injury, age, cardiovascular disease, and vasopressors directly associated with ICU outcome, albeit with moderate robustness (Supplementary Figure 1). Furthermore, obtundation at ICU admission directly and robustly interacted with ICU outcome, concurrent with our regression model findings.

\section{Discussion}

This study is one of few performed in Brazilian ICUs to examine admission factors associated with ICU mortality in patients with HAIs. Interestingly, while prior studies note an HAI rate of $20 \%$ to $50 \%$ in the ICU, ${ }^{13}$ only $13.6 \%$ of patients admitted to our ICU developed an HAI. Given the similar distribution of infection type in our ICU to other studies, it remains unclear whether there are unit or patient specific factors that account for this lower than expected HAI rate. Moreover, while increased length of stay increases risk of HAIs in general, we also found an increased risk of death in those with prolonged hospitalization. Furthermore, prior studies noted an association between chronic heart failure and increased risk of death in those with respiratory infections acquired in the ICU. ${ }^{14-16}$ In contrast to these findings, all patients with chronic heart failure and HAI in our cohort survived.

The substantial mortality rate of $46 \%$ found in our study is comparable to that found in HAI studies outside of Brazil, ${ }^{17,18}$ though others have reported lower mortality rates possibly related to different health-care systems and study designs. ${ }^{19-21}$ One previous study performed in a general hospital population in Brazil noted a mortality rate of $27.6 \%$ and found that the relevant prognostic factors in the occurrence of death were underlying illness $(\mathrm{HR}=3.71)(p=0.056)$, admission to the $\operatorname{ICU}(\mathrm{HR}=1.61)$ and the use of corticosteroids $(\mathrm{HR}=3.71){ }^{22}$

Whether site of infection impacts mortality has evolved as HAI definitions have been refined and revised. 
Table I Patient Characteristics and ICU Admission Data

\begin{tabular}{|c|c|c|c|}
\hline Characteristics & Death $(n=76)$ & Discharge $(n=89)$ & $p$-value \\
\hline Male & $43(56.6 \%)$ & $45(50.6 \%)$ & 0.44 \\
\hline Age, mean $\pm S D$ & $75 \pm 13$ & $65 \pm 18$ & $<0.001^{\mathrm{a}}$ \\
\hline Re-admission to ICU. n (\%) & 17 (22.4\%) & $18(20.2 \%)$ & 0.737 \\
\hline Re-admission to ICU within $48 \mathrm{~h} \mathrm{n}$ (\%) & $3(3.9 \%)$ & $0(0)$ & 0.059 \\
\hline Location prior to admission & & & 0.122 \\
\hline Emergency & $35(46.1 \%)$ & $49(55.1 \%)$ & \\
\hline Surgery & $7(9.2 \%)$ & II (I2.4\%) & \\
\hline Hospital ward & 18 (23.7\%) & $10(11.2 \%)$ & \\
\hline Transfer from different hospital & $14(18.4 \%)$ & $19(21.3 \%)$ & \\
\hline \multicolumn{4}{|l|}{ Comorbidities n (\%) } \\
\hline Chronic heart failure & $0(0 \%)$ & $8(9 \%)$ & 0.007 \\
\hline Chronic kidney disease & II (I4.5\%) & $21(23.6 \%)$ & 0.136 \\
\hline Cirrhosis & $2(2.9 \%)$ & $\mathrm{I}(\mathrm{I} . \mathrm{l} \%)$ & 0.47 \\
\hline Diabetes mellitus & $32(42.1 \%)$ & $36(40.4 \%)$ & 0.829 \\
\hline Cardiovascular disease & 17 (22.4\%) & $28(31.5 \%)$ & 0.191 \\
\hline Previous stroke & $18(23.7 \%)$ & $18(20.2 \%)$ & 0.592 \\
\hline Dementia & $10(13.2 \%)$ & $6(6.7 \%)$ & 0.165 \\
\hline Performance status $\mathrm{n}(\%)$ & & & 0.06 \\
\hline Completely independent & 57 (75\%) & 75 (84.3\%) & \\
\hline Partially independent & $6(7.9 \%)$ & $9(10.1 \%)$ & \\
\hline Fully dependent & $13(17.1 \%)$ & $5(5.6 \%)$ & \\
\hline \multicolumn{4}{|l|}{ Admission clinical data } \\
\hline SAPS3 predicted mortality (median, IQR) & $30.51(20.4-49.3)$ & $15.9 \mid(8.9-25.7)$ & $<0.001$ \\
\hline Respiratory rate & $20(18-25)$ & $20(18-22)$ & 0.23 \\
\hline Temperature $\left({ }^{\circ} \mathrm{C}\right)$ & $36(35.1-36.6)$ & $36(35.1-36.6)$ & 0.833 \\
\hline Mean arterial pressure $(\mathrm{mmHg})($ mean $\pm \mathrm{SD})$ & $92.61(74.5-107.5)$ & $100.02(83.5-116.17)$ & 0.025 \\
\hline Glasgow coma score & $14(1 \mid-15)$ & $15(13-15)$ & 0.012 \\
\hline Hematocrit & $33 \pm 8.1$ & $32.7 \pm 8.2$ & $0.828^{\mathrm{a}}$ \\
\hline White blood cell $\left(\dot{\times} 10^{3}\right)$ & $12.1(9-17.1)$ & $12.4(8.3-17.1)$ & 0.83 \\
\hline Platelets $\left(\dot{\times} 10^{3}\right)$ & $206(147-308)$ & $272(194-343)$ & 0.014 \\
\hline Lactate $(\mathrm{mmol} / \mathrm{L})$ & $1.3(1-1.9)$ & $1.2(0.8-1.9)$ & 0.174 \\
\hline Creatinine (mg/dL) & $0.9(0.6-2.3)$ & $0.8(0.6-2.3)$ & 0.606 \\
\hline Admission C-reactive protein (mg/L) & $82.20(17.30-129)$ & $30.25(10.14-93.30)$ & 0.021 \\
\hline Peak C-reactive protein $(\mathrm{mg} / \mathrm{L})$ & $200(\mid I 5.5-20 I)$ & $108(79.3-198)$ & $<0.001$ \\
\hline \multicolumn{4}{|l|}{ Outcomes and complications } \\
\hline ICU length of stay (days) (median, IQR) & $22(\mid 4-47)$ & $17(8-29)$ & 0.025 \\
\hline Mechanical ventilation & $34(44.7 \%)$ & $25(28.1 \%)$ & 0.026 \\
\hline Vasopressors & $15(19.7 \%)$ & $5(5.6 \%)$ & 0.06 \\
\hline Acute kidney injury & $12(15.8 \%)$ & $6(6.7 \%)$ & 0.063 \\
\hline Obtundation & $50(65.8 \%)$ & $36(40.4 \%)$ & 0.001 \\
\hline Septic shock & $9(11.8 \%)$ & $2(2.2 \%)$ & 0.014 \\
\hline
\end{tabular}

Note: ${ }^{\text {a } C h i-s q u a r e d ~ t e s t . ~}$

Specifically, prior work noted that catheter-associated urinary tract infections acquired in the ICU may not increase risk of death compared to those without these infections. $^{23}$ This finding contrasts with CLABSI and HAP, which previously were associated with increased mortality in the ICU when compared to their noninfected counterparts. It may be that these infections lead to a higher bacterial burden, are characterized by more virulent and resistant pathogens or related to host factors that reflect increased severity of ICU disease (central vascular 


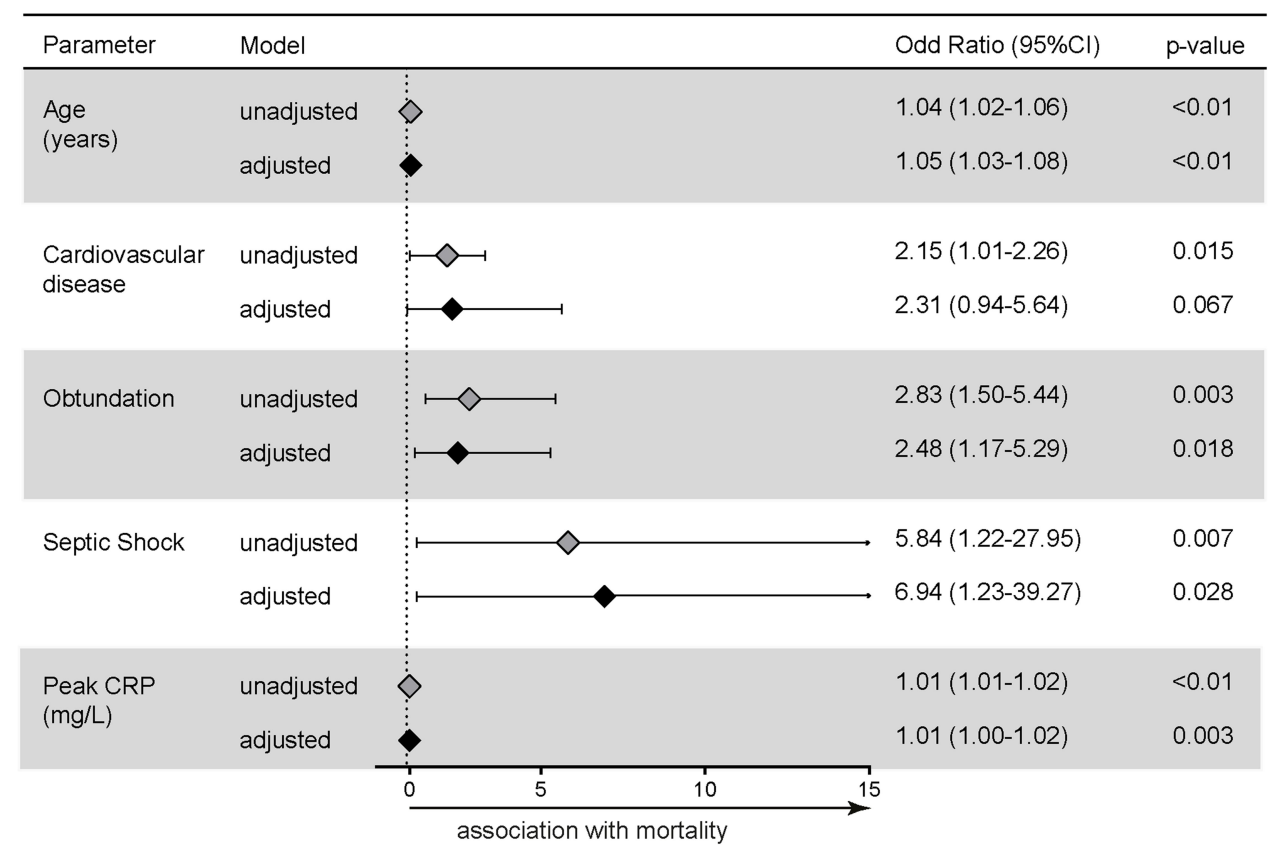

Figure I Adjusted and unadjusted multivariate regression model for ICU mortality. Univariate analysis yielded unadjusted odds of death. Multivariate regression adjusted for differences in baseline characteristics (variables with $p<0.1$ in univariate comparisons).

access, intubation). While older studies noted a shift towards gram-positive bacterial infections in $\mathrm{HAI},{ }^{24,25}$ recent studies demonstrate that over $50 \%$ of ICU nosocomial infections are due to gram-negative bacteria. ${ }^{26,27}$ It is known that multidrug resistant bacteria are a major health care problem and associated with increased mortality, however, only a small fraction of deaths have been directly attributed to them in infected patients by previous studies. ${ }^{28,29}$ Interestingly, our study found no significant difference in mortality based on site of infection, type of infecting pathogen or antibiotic resistance. Given the limited number of patients with multiple infections during the same hospitalization, our study may be underpowered to detect a mortality difference based on number of HAIs.

Complications beyond mortality in the ICU including need for mechanical ventilation and use of vasopressors, were significantly different in survivors compared with nonsurvivors in univariate analysis in our study, similar to another study performed in Ethiopia. ${ }^{30}$

Despite the strengths of our study, there are several limitations that require acknowledgement. As a single center study performed over a limited time, there was an unexpected paucity of HAIs that may account for our modest sample size. Population and local characteristics could be potential confounders, since previous studies have shown that factors such as type of admission and length of stay are associated with multiresistant infections. ${ }^{31}$ Exclusion of patients with missing data, either microbiologic or clinical led to a reduced sample size. Balanced against this smaller sample is a robust and detailed record for each patient that significantly enriched the analytical potential of our study. Moreover, rigorous approaches were utilized to assess interaction between variables and mortality to account for potentially confounding and misleading findings. Finally, an analysis on the appropriateness of the given antibiotics would have been of great value to this study, especially because a tendency of greater infection rates with multiresistant pathogens has been independently associated with use of certain antibiotics. ${ }^{29}$ Unfortunately, given the low number of individuals with recorded data matching identification of specific pathogens, the antimicrobials used and the drug resistance profile, we could not perform analyses separating such categories.

\section{Conclusion}

Individuals who develop HAI during hospitalization in the ICU had a greater chance of death when they presented, on admission, with altered consciousness or met the criteria for septic shock. These findings highlight the importance of early recognition and treatment of those at risk of death with HAIs in a vulnerable ICU population. Findings from this study may help intensivists identify patients at greatest 
risk of death from HAIs to guide targeted ICU monitoring and rapid treatment interventions.

\section{Abbreviations}

BUN, blood urea nitrogen; BMI, body mass index; UTI, catheter associated urinary tract infections; CLABSI, central line associated bloodstream infections; HAI, hospital acquired infections; ICU, intensive care units; ; MAP, mean arterial pressure; ANVISA, national guidelines; SSI, surgical site infection; VAP, ventilator associated pneumonia; WBC, white blood cell.

\section{Data Sharing Statement}

The datasets used and/or analyzed during the current study are available from the corresponding author on reasonable request.

\section{Ethics Approval and Consent}

The study was approved by the Research Ethics Committee of Hospital Ana Nery under the number 2,571,265 and CAAE 52,892,315.1.0000.0045. This same Ethics Committee approved the waiver of the patient's informed consent, with the justification that this is a retrospective and analytical observational study whose information is obtained from medical records and that the data are analyzed anonymously, according to the rules regulations of the national health council (no. 466/12). The study was in compliance with the Declaration of Helsinki. Privacy statement: the authors guarantee patient data confidentiality.

\section{Acknowledgments}

The authors thank the research groups GEMINI, from the Núcleo de Ensino e Pesquisa from Hospital da Cidade, and MONSTER, Osvaldo Cruz Foundation.

\section{Author Contributions}

All authors made a significant contribution to the work reported, whether that is in the conception, study design, execution, acquisition of data, analysis and interpretation, or in all these areas; took part in drafting, revising or critically reviewing the article; gave final approval of the version to be published; have agreed on the journal to which the article has been submitted; and agree to be accountable for all aspects of the work.

\section{Funding}

The study was supported by the Intramural Research Program from Hospital da Cidade and from the Fundação
Oswaldo Cruz. The work of B.B.A. was supported by the the Conselho Nacional de Desenvolvimento Científico e Tecnológico (CNPq; senior scientist fellowship). KFF received a fellowship from the Programa Nacional de Pós-Doutorado, Coordenação de Aperfeiçoamento de Pessoal de Nível Superior (CAPES, finance code 001). MBA and TAC received research fellowships from Fundação de Amparo à Pesquisa do Estado da Bahia (FAPESB). The funders had no role in study design, data collection and analysis, decision to publish, or preparation of the manuscript.

\section{Disclosure}

The authors report no conflicts of interest in this work.

\section{References}

1. Ministério da Saúde.. Portaria 2.616, de 12 de maio de 1998, Diretrizes para prevenção e controle das infecções hospitalares. 1998. Available from: https://bvsms.saude.gov.br/bvs/saudelegis/ gm/1998/prt2616_12_05_1998.html. Accessed February 4, 2020.

2. Haque M, Sartelli M, McKimm J, Bakar MA. Health care-associated infections an overview. Infect Drug Resist. 2018;11:2321-2333. doi:10.2147/IDR.S177247

3. van Duin D, Paterson DL. Multidrug-Resistant Bacteria in the Community: Trends and Lessons Learned. Infect Dis Clin North Am. 2016;30(2):377-390. doi:10.1016/j.idc.2016.02.004

4. Suetens C, Latour K, Kärki T, et al. Prevalence of healthcare-associated infections, estimated incidence and composite antimicrobial resistance index in acute care hospitals and long-term care facilities: results from two european point prevalence surveys, 2016 to 2017. Eurosurveillance. 2018;23(46):1-18. doi:10.2807/ 1560-7917.ES.2018.23.46.1800516

5. da Silva EP, Duarte VDC, Soares MM, et al. Survival analysis of patients with sepsis in Brazil. Rev Soc Bras Med Trop. 2019;52:1-4. doi:10.1590/0037-8682-0121-2018

6. Souza ES, Belei RA, Carrilho CMD, et al. Mortality and risks related to healthcare-associated infection. Texto Context - Enferm. 2015;24 (1):220-228. doi:10.1590/0104-07072015002940013

7. Turrini RNT. Infecção hospitalar e mortalidade. Rev Esc Enferm USP. 2002;36(2):177-183. doi:10.1590/S0080-62342002000200011

8. Oliveira AC, Paula AO, Iquiapaza RA, Lacerda ACDS. Infecções relacionadas à assistência em saúde e gravidade clínica em uma unidade de terapia intensiva. Rev Gaúcha Enferm. 2012;33(3): 89-96. doi:10.1590/S1983-14472012000300012

9. McAuley AK, Sanfilippo PG, Hewitt AW, et al. Vitreous biomarkers in diabetic retinopathy: A systematic review and meta-analysis. J Diabetes Complications. 2014;28(3):419-425. doi:10.1016/j.jdiacomp.2013.09.010

10. Yilmaz MI, Sonmez A, Saglam M, et al. Ramipril lowers plasma FGF-23 in patients with diabetic nephropathy. Am J Nephrol. 2014;40 (3):208-214. doi:10.1159/000366169

11. Maertzdorf J, McEwen G, Weiner J, et al. Concise gene signature for point of care classification of tuberculosis. EMBO Mol Med. 2016;8 (2):86-95. doi:10.15252/emmm.201505790

12. Zak DE, Penn-Nicholson A, Scriba TJ, et al. A blood RNA signature for tuberculosis disease risk: a prospective cohort study. Lancet. 2016:387(10035); 2312-2322. doi:10.1016/S01406736(15)01316-1 
13. ECDC. Surveillance of healthcare-associated infections in Europe 2007 [Internet]; 2007. 1-134. Available from: ecdc.europa.eu/en/pub lications/Publications/120215_SUR_HAI_2007.pdf.

14. Singh JA, Yu S, et al. Utilization due to chronic obstructive pulmonary disease and its predictors: a study using the U.S. National Emergency Department Sample (NEDS). Respir Res. 2016:17(1); 1-9. doi:10.1186/s12931-015-0319-y

15. Alp E, Güven M, Yildiz O, Aygen B, Voss A, Doganay M. Incidence, risk factors and mortality of nosocomial pneumonia in intensive care units: A prospective study. Ann Clin Microbiol Antimicrob. 2004;3:1-7. doi:10.1186/1476-0711-3-17

16. Thomsen RW, Kasatpibal N, Riis A, Nørgaard M, Sørensen HT. The impact of pre-existing heart failure on pneumonia prognosis: population-based cohort study. J Gen Intern Med. 2008;23 (9):1407-1413. doi:10.1007/s11606-008-0672-3

17. Kolpa M, Walaszek M, Gniadek A, Wolak Z, Dobroś W. Incidence, microbiological profile and risk factors of healthcare-associated infections in intensive care units: A 10 year observation in a provincial hospital in southern Poland. Int $J$ Environ Res Public Health. 2018;15(1):1-16. doi:10.3390/ijerph15010112

18. Laupland KB, Kirkpatrick AW, Church DL, Ross T, Gregson DB. Intensive-care-unit-acquired bloodstream infections in a regional critically ill population. J Hosp Infect. 2004;58(2):137-145. doi:10.10 16/j.jhin.2004.06.007

19. Avci M, Ozgenc O, Coskuner SA, Olut AI. Hospital acquired infections (HAI) in the elderly: comparison with the younger patients. Arch Gerontol Geriatr. 2012;54(1):247-250doi:10.1016/j.archger.20 11.03 .014

20. Vrijens F, Hulstaert F, Devriese S, Van De Sande S. Hospitalacquired infections in Belgian acute-care hospitals: an estimation of their global impact on mortality, length of stay and healthcare costs. Epidemiol Infect. 2012;140(1):126-136. doi:10.1017/S0950268811 000100

21. Hautemanière A, Florentin A, Hartemann P, Hunter PR. Identifying possible deaths associated with nosocomial infection in a hospital by data mining. Am J Infect Control. 2011;39(2):118-122. doi:10.1016/j. ajic.2010.04.216
22. Gusmão MEN. Infecção Hospitalar: Mortalidade, Sobrevida e Fatores Prognósticos No Hospital Universitário Professor Edgard Santos/UFBA. Universidade Federal da Bahia. 2008:153.

23. Laupland KB, Zygun DA, Davies HD, Church DL, Louie TJ, Doig CJ. Incidence and risk factors for acquiring nosocomial urinary tract infection in the critically ill. J Crit Care. 2002;17(1):50-57. doi:10.1053/jcrc.2002.33029

24. Friedman G, Silva E, Vincent J-L. Has the mortality of septic shock changed with time? Crit Care Med. 1998;26(12):2078-2086.

25. Wisplinghoff $\mathrm{H}$, Bischoff $\mathrm{T}$, Tallent SM, Seifert H, Wenzel RP, Edmond MB. Nosocomial bloodstream infections in US hospitals: analysis of 24,179 cases from a prospective nationwide surveillance study. Clin Infect Dis. 2004;39(3):309-317.

26. Vincent J, Rello J, Marshall J, et al. The extended prevalence of infection in the ICU study: EPIC II. Crit Care. 2009;49.

27. Richards MJ, Edwards JR, Culver DH, Gaynes RP, Surveillance I. Nosocomial infections in combined medical surgical Intensive Care Units in the United States. Infect Control Hosp Epidemiol. 2010;21 (8):510-515. doi:10.1086/501795

28. Cassini A, Högberg LD, Plachouras D, et al. Attributable deaths and disability-adjusted life-years caused by infections with antibiotic-resistant bacteria in the EU and the European Economic Area in 2015: a population-level modelling analysis. Lancet Infect Dis. 2019;19(1):56-66.

29. Neubeiser A, Bonsignore M, Tafelski S, et al. Mortality attributable to hospital acquired infections with multidrug-resistant bacteria in a large group of German hospitals. J Infect Public Health. 2020;13(2):204-210.

30. Ali S, Birhane M, Bekele S, et al. Healthcare associated infection and its risk factors among patients admitted to a tertiary hospital in Ethiopia: longitudinal study. Antimicrob Resist Infect Control. 2018;7:2. doi:10.1186/s13756-017-0298-5

31. Graffunder EM. Risk factors associated with nosocomial methicillin-resistant Staphylococcus aureus (MRSA) infection including previous use of antimicrobials. J Antimicrob Chemother. 2002;49(6):999-1005.
Infection and Drug Resistance

\section{Publish your work in this journal}

Infection and Drug Resistance is an international, peer-reviewed openaccess journal that focuses on the optimal treatment of infection (bacterial, fungal and viral) and the development and institution of preventive strategies to minimize the development and spread of resistance. The journal is specifically concerned with the epidemiology of antibiotic resistance and the mechanisms of resistance development and diffusion in both hospitals and the community. The manuscript management system is completely online and includes a very quick and fair peerreview system, which is all easy to use. Visit http://www.dovepress.com/ testimonials.php to read real quotes from published authors. 